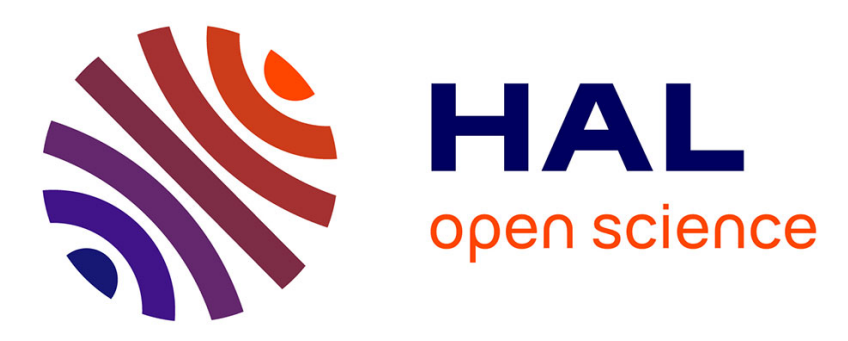

\title{
Optimization of jet parameters to control the flow on a ramp
}

Emmanuel Guilmineau, Régis Duvigneau, Jérémie Labroquère

\section{To cite this version:}

Emmanuel Guilmineau, Régis Duvigneau, Jérémie Labroquère. Optimization of jet parameters to control the flow on a ramp. Comptes rendus de l'Académie des sciences. Série IIb, Mécanique, 2014, 342 (6-7), pp.363-375. 10.1016/j.crme.2013.12.009 . hal-01025269

\section{HAL Id: hal-01025269 \\ https://hal.inria.fr/hal-01025269}

Submitted on 22 Jul 2014

HAL is a multi-disciplinary open access archive for the deposit and dissemination of scientific research documents, whether they are published or not. The documents may come from teaching and research institutions in France or abroad, or from public or private research centers.
L'archive ouverte pluridisciplinaire HAL, est destinée au dépôt et à la diffusion de documents scientifiques de niveau recherche, publiés ou non, émanant des établissements d'enseignement et de recherche français ou étrangers, des laboratoires publics ou privés. 


\title{
Optimization of jet parameters to control the flow on a ramp.
}

\author{
E. Guilmineau ${ }^{\mathrm{a}, *}$, R. Duvigneau ${ }^{\mathrm{b}}$, J. Labroquère ${ }^{\mathrm{b}}$ \\ ${ }^{a}$ LHEEA, CNRS UMR 6598, Ecole Centrale de Nantes \\ 1 rue de la Noё, BP 92101, 44321 Nantes Cedex 3, France \\ ${ }^{b}$ INRIA Sophia Antipolis-Méditerrannée, OPALE Project-Team \\ 2004 route des Lucioles, 06902 Sophia-Antipolis, France
}

\begin{abstract}
This study deals with the use of optimization algorithms to determine efficient parameters of flow control devices. To improve the performance of systems characterized by detached flows and vortex shedding, the use of flow control devices such as oscillatory jets, are intensively studied. However, the determination of efficient control parameters is still a bottleneck for industrial problems. Therefore, we propose to couple a global optimization algorithm with an unsteady flow simulation to derive efficient flow control rules. We consider as test case an backward facing step with a slope of $25^{\circ}$, including a synthetic jet actuator. The aim is to reduce the time-averaged recirculation length behind the step by optimizing the jet blowing/suction amplitude and frequency
\end{abstract}

Keywords: Flow control, Optimization, Ramp

\section{Introduction}

Flow-control technology has been widely researched to improve the aerodynamic performance of transportation systems such as aircrafts and cars. The common objectives in many cases are to prevent massive flow separations. Actuator devices, such as synthetic jets or vortex generators, have proved their ability to modify the flow dynamics. However, the determination of efficient flow control parameters, in term of location frequency,

\footnotetext{
*Corresponding author: Emmanuel.Guilmineau@ec-nantes.fr
} 
amplitude, $\ldots$, is tedious and highly problem dependent $[1,2]$. To overcome this issue, the numerical simulation of controlled flows is often considered to determine optimal control parameters, and the use of an automated optimization procedure is more and more observed $[3,4]$. Several studies have shown that the simulation of controlled flows is a difficult task, since result may be dependent on the turbulence close used $[5,6]$ but also on numerical errors [6].

Therefore, this paper presents numerical results in the context of the optimization of flow control parameters for the flow on a ramp.

\section{Flow solver}

The ISIS-CFD flow solver, developed by "Ecole Centrale de Nantes" and CNRS, solves the incompressible unsteady Reynolds-Averaged Navier-Stokes equations. This solver is based on finite volume method to build a spatial discretization for the transport equations.

The incompressible unsteady Reynolds-Averaged Navier-Stokes equations can be written (using the generalized form of Gauss' theorem) as:

$$
\begin{gathered}
\frac{\partial}{\partial t} \int_{V} \rho d V+\int_{S} \rho\left(\vec{U}-\vec{U}_{d}\right) \cdot \vec{n} d S=0 \\
\frac{\partial}{\partial t} \int_{V} \rho U_{i} d V+\int_{S} \rho U_{i}\left(U_{j}-U_{d j}\right) \cdot n_{j} d S=\int_{S}\left(\tau_{i j} n_{j}-p n_{i}\right) d S
\end{gathered}
$$

where $V$ is the domain of interest, or control volume, bounded by a closed surface $S$ moving at a velocity $\vec{U}_{d}$ with a unit outward normal vector $\vec{n}$ where $n_{j}$ is the $j^{\text {th }}$ component. $\vec{U}$ and $p$ are respectively the velocity and pressure fields. $\tau_{i j}$ are the components of the Reynolds stress tensor.

All flow variables are stored at the geometric center of arbitrary shaped cells. Volume and surface integrals are evaluated with second-order accurate approximations. The face-based method is generalized to two-dimensional or three-dimensional unstructured meshes for which non-overlapping control volumes are bounded by an arbitrary number of constitutive faces, that means cells can be polyhedral. A centered scheme is used for the diffusion terms, whereas for the convective fluxes, the Gamma Differencing Scheme (GDS) [7] is used for this study. Through a Normalized Variable Diagram 
(NVD) analysis [8], this scheme enforces local monotonicity and convection boundedness criterion. For more details, see Queutey and Visonneau [9].

The velocity field is obtained from the momentum conservation equations, and the pressure field is extracted from the mass conservation constraint, or continuity equation, transformed into a pressure-equation. The pressure equation is obtained in the spirit of Rhie and Chow [10]. Momentum and pressure equations are solved in a segregated manner as in the SIMPLE coupling procedure [11].

A second-order backward difference scheme is used for time discretization. All spatial terms appearing in equations (1a) and (1b) are treated in a fully implicit manner. In this paper, the geometry is fixed. Therefore, the velocity $\vec{U}_{d}$ in the equations (1a) and (1b) is null.

In the case of turbulent flows, additional transport equations for modeled variables are discretized and solved using the same principles. Various turbulence closures are implemented. The method features sophisticated turbulence models: apart from the classical two-equation $\mathrm{k}-\varepsilon$ and $\mathrm{k}-\omega$ models, the anisotropic two-equation Explicit Algebraic Reynolds Stress Model (EARSM), as well as Reynolds Stress Transport Models, are available, see [12] and [13]. Recently, a Detached Eddy Simulation (DES) approach has been introduced, see [14].

We consider actuations based on synthetic jets. The actuation is implemented as boundary conditions. The velocity is imposed on the jet boundary and is defined as:

$$
\mathbf{U}=U_{j} A(X) \sin (\omega t) \mathbf{d}_{j}
$$

with $A(x)$ a unit profile function, $U_{j}$ the amplitude, $\omega$ the angular frequency with $\omega=2 \pi f_{j}$ where $f_{j}$ is the frequency of the synthetic jet, and $\mathbf{d}_{j}$ the direction of the jet. In this study, $A(X)$ is a sine squared function and $\mathbf{d}_{j}$ is perpendicular to the boundary.

\section{Optimizer}

A surrogate-based optimizer, included in the FAMOSA optimization toolbox developed at INRIA by Opale Project-Team, is used for this study. It 
is based on the construction of a kriging model to describe the variation of the objective function value, for example the recirculation length or the drag coefficient, with respect to control parameters. Kriging models, also called Gaussian process models, belong to response surface models, that allow to predict a function value $f$ at a given point $x$, on the basis of a set of known function values $\boldsymbol{F}_{\boldsymbol{N}}=\left\{f_{1}, f_{2}, \cdots, f_{N}\right\}$ at some points $\boldsymbol{X}_{\boldsymbol{N}}=$ $\left\{x_{1}, x_{2}, \cdots, x_{N}\right\}$, that are stored in a database. $\boldsymbol{F}_{\boldsymbol{N}}$ is assumed to be one realization of a multivariate Gaussian process [15] which has a joint Gaussian distribution

$$
p\left(\boldsymbol{F}_{\boldsymbol{N}} \mid C_{N}, \boldsymbol{X}_{\boldsymbol{N}}\right)=\frac{\exp \left(-\frac{1}{2} \boldsymbol{F}_{\boldsymbol{N}}^{T} C_{N}^{-1} \boldsymbol{F}_{\boldsymbol{N}}\right)}{\sqrt{(2 \pi)^{N} \operatorname{det}\left(C_{N}\right)}}
$$

for any collections of inputs $\boldsymbol{X}_{N}$. $C_{N}$ is the $N \times N$ covariance matrix, whose elements $C_{m n}$ give the correlation between the function values $f_{m}$ and $f_{n}$ obtained at points $x_{m}$ and $x_{n}$. We assume that these values are correlated, since they correspond to underlying physical phenomena. This is expressed in terms of a correlation function $k$, i.e., $C_{m n}\left(x_{m}, x_{n}\right)=\operatorname{cov}\left(f_{m}, f_{n}\right)$ $=k\left(x_{m}, x_{n} ; \Theta\right)$ with $\Theta$ a set of hyper-parameters that are calibrated to maximize the likelihood of the observations.

It can be shown [16] that the probability density for the function value at a new point is

$$
p\left(f_{N+1} \mid\left(\boldsymbol{X}_{\boldsymbol{N}}, \boldsymbol{F}_{\boldsymbol{N}}\right), C_{N}, x_{N+1}\right) \propto \exp \left[-\frac{\left(f_{N+1}-\hat{f}_{N+1}\right)^{2}}{2 \hat{\sigma}_{f_{N+1}}^{2}}\right]
$$

where

$$
\hat{f}_{N+1}=\boldsymbol{k}_{N+\mathbf{1}}^{T} C_{N}^{-1} \boldsymbol{F}_{\boldsymbol{N}}, \quad \hat{\sigma}_{f_{N+1}}^{2}=\kappa-\boldsymbol{k}_{\boldsymbol{N}+\mathbf{1}}^{T} C_{N}^{-1} \boldsymbol{k}_{N+\mathbf{1}}
$$

with $\kappa=k\left(x_{N+1}, x_{N+1} ; \Theta\right)$ and $\boldsymbol{k}_{N+\mathbf{1}}=\left[k\left(x_{1}, x_{N+1} ; \Theta\right), \cdots, k\left(x_{N}, x_{N+1} ; \Theta\right)\right]^{T}$.

Thus, the probability density for the function value at the new point $x_{N+1}$ is also Gaussian with mean $\hat{f}_{N+1}$ and standard deviation $\hat{\sigma}_{f_{N+1}}$. Therefore, the most likely value at the new point $x_{N+1}$ is $\hat{f}_{N+1}$. This value will be considered as the prediction of the kriging model. The variance $\hat{\sigma}_{f_{N+1}}^{2}$ can be interpreted as a measure of uncertainty in the value prediction. The function value can expected to vary in some range like $[\hat{f}-3 \hat{\sigma}, \hat{f}+3 \hat{\sigma}]$. 
The optimization strategy used in this study is based on the iterative construction of a kriging model. The use of such a model for optimization must be an iterative process since it is not possible to build a model accurate enough to find the optimal parameters in only one step. The model should be updated with the results from flow simulation until some convergence criterion is fulfilled. Therefore, the algorithm is organized in two phases. During the first one, an initial a priori database is constructed, that gathers the flow response (objective function values) corresponding to different control parameter values. The control parameters are chosen in order to explore uniformly the search space, according to a Design Of Experiments (DOE) method. During the second phase, a kriging model is constructed on the basis of available data and is used to determine which flow simulations should be carried out and added into the database. This second phase is then repeated until convergence of the algorithm, as illustrated in Figure 1.

The robustness and efficiency of this algorithm depends critically on the choice of the new simulations to be carried out during the second phase. To obtain satisfactory results, the capability of a kriging model to predict the uncertainty related to value predictions is used. Indeed, for a given design vector $x$, a kriging model provides not only a prediction of the function value $\hat{f}(x)$, but also an estimation of the uncertainty of this prediction $\sigma(x)$. Therefore, one can use this knowledge to determine not only the point that minimizes the model, but also areas for which the model is uncertain, i.e. of poor quality. Evaluating such points promotes the minimization of the cost function as well as the improvement of the kriging model. Details on the enrichment procedure can be found in [17]

\section{Test-case}

The ramp is a backward facing step with an slope of $25^{\circ}$, and is selected to test the optimization method on a flow control problem. This test-case is a configuration chosen by the French research group "Flow Separation Control", entitled in French "GDR Contrôle des décollements". This configuration is represented in Figure 2.

The step height $h$ is equal to $100 \mathrm{~mm}$ and the slope of the step is equal to 25 degrees. Two positions of the synthetic jet are investigated. The first is located just after the step. This position is called configuration A. The 
second is just before the step and is called configuration B. In both cases, the jet direction is normal to the wall. The width of the slot is $d=0.5 \mathrm{~mm}$, i.e. $0.05 h$.

The inlet of the computational domain is located at $11.8 h$ of the corner of the step and the outlet at $25 h$. The mesh is generated by Hexpress ${ }^{\mathrm{TM}}$, an automatic unstructured mesh generator. This software generates meshes containing only hexahedrons. The mesh contains 73502 nodes and 71375 cells.

At the inlet, a uniform velocity $U_{\text {ref }}=20 \mathrm{~m} / \mathrm{s}$, which corresponds to a Reynolds number of $\mathrm{Re}=1.23 \times 10^{5}$ with respect to the height of the ramp, $h$, is imposed as well as the top of the computational domain. At the outlet, the pressure is imposed. The walls have a no-slip condition and the boundary layer is refined at the wall to fulfill the $y^{+}<1$ criterion, as shown Figure 4.

\section{Results}

For all the numerical simulations, the turbulence model used is the $\mathrm{k}-\omega$ SST model of Menter.

\subsection{Non controlled configuration}

A configuration without actuation is firstly studied. In this case, the jet boundary condition is replaced by a wall.

Figure 5 presents a comparison of the velocity profile between the experimental data [18] and numerical results at $\mathrm{X} / h=-2.4$. We observe a good agreement between the experimental data and the numerical result. This comparison confirms that the inlet is sufficient far to get the correct boundary thickness.

Figure 6 shows the streamlines obtained by the numerical simulation and in experiments. A massive separation exists and any vortex shedding appears. The recirculation is characterized by a length, called $L_{r}$. The nu-

merical simulation predicts $L_{r} / h=5.333$. The center of the recirculation is located at $X_{C} / \mathrm{h}=2.659$ and $Y_{C} / \mathrm{h}=0.455$. 


\subsection{Controlled configuration}

A synthetic jet is used to reduce the recirculation length. The period of the synthetic jet, called $T_{j}$, is described with 200 time steps and the numerical simulation is carried out with 20 jet periods. The averaged flow is obtained by using the last five periods.

The optimization parameters considered in this study are restricted to the amplitude and the frequency of the synthetic jet. To construct the a priori database used to explore the design space, the parameters of the synthetic jet are supposed to vary in the following ranges:

- $15 \mathrm{~m} / \mathrm{s} \leq U_{j} \leq 100 \mathrm{~m} / \mathrm{s}$ for the amplitude,

- $50 \mathrm{~Hz} \leq f_{j} \leq 600 \mathrm{~Hz}$ for the frequency.

For both jet configurations, an initial of 16 flows is generated using an optimized Latin Hypercube Sampling (LHS), as illustrated in Figure 7.

The time history of the optimization process is represented in Figure 8 for both configurations. The first step of optimization loop gives the jet configuration which leads to the minimum recirculation.

The meta-models for both configurations are presented in Figures 9 and 10, for the configuration $\mathrm{A}$ and the configuration $\mathrm{B}$ respectively. For the configuration A, the best parameters of the synthetic jet are $f_{j}=77.330 \mathrm{~Hz}$ and $U_{j}=63.760 \mathrm{~m} / \mathrm{s}$. So, the Strouhal number is $S t=f_{j} \times h / U_{j} \simeq 0.387$. These parameters deal to the moment coefficient $C_{\mu}=d U_{j} / L_{r} U_{\text {ref }}=0.9 \%$ and the reduced frequency $F^{+}=f_{j} L_{r} / U_{\text {ref }}=2.06$. For the configuration B, the best parameters are $f_{j}=62.086 \mathrm{~Hz}, U_{j}=88.193 \mathrm{~m} / \mathrm{s}$ and the Strouhal number $S t \simeq 0.310$. for this configuration, the non-dimensional parameters are $C_{\mu}=1.8 \%$ and $F^{+}=1.66$. For both configurations, the best parameters are obtained for a frequency of the synthetic jet close to the boundary of the design space. We also observe that the meta-model begins to oscillate. The possible sources of oscillations are the interpolating model that becomes too complex when the new points close together are added to the database and the difficulty to maximize the kriging model. 
Figure 11 presents the streamlines of the averaged flow obtained with the best parameters of the synthetic jet. With these jet parameters, the recirculation length decreases. For the configuration A, the length is $L_{r}=4.004 \mathrm{~h}$ while for the configuration $\mathrm{B}, L_{r}$ is equal to $4.061 \mathrm{~h}$. In both cases, a reduction of the time-averaged recirculation of about $24 \%$ is observed.

Figure 12 presents a comparison of the pressure coefficient for the non controlled case and the pressure obtained with the best parameters of the synthetic jet for each position of the actuator. The presence of the synthetic jet manifests by a significant increase in the suction peak and an extended domain of adverse pressure gradient.

Figures 13 and 14 give some snapshots of the flow on one synthetic jet period for the configuration $\mathrm{A}$ and the configuration $\mathrm{B}$, respectively. For both cases, the flow is obtained with the best parameters of the actuator. The flow evolution is similar for both jet configurations. Three recirculation bubbles are created during a time period of the actuator, and for each time step, the bubble position is similar between the two configurations.

Figures 15 and 16 present a zoom close the actuator for the previous snapshots. When the blowing is activated, a bubble is created, see Figure 15(a) and 16(a). However, this bubble is more large with the configuration B. When the jet velocity is maximum, see Figure 15(b) and 16(b), the initial bubble goes down slides down the ramp. According to the position of the synthetic jet, the flow is different. With the configuration $\mathrm{A}$, another bubble is present above the first bubble. It is not the case with the configuration B. With this configuration, a separation is present in front of the jet. Then, when the suction is activated, the flow is similar.

\section{Conclusions}

In this study, the kriging-based optimization algorithm of FAMOSA has been coupled with the unsteady Reynolds-averaged Navier-Stokes solver ISISCFD. This approach has been applied to optimize the amplitude and frequency of a synthetic jet in order to shorten the time-averaged recirculation length behind a ramp. Two positions of the actuator have been investigated: one just after the corner of the ramp and the second just before. Each configuration with its own jet parameters leads to the same reduction of the 
averaged bubble. The best parameters for the configuration with the actuator after the corner of ramp are $C_{\mu}=0.9 \%$ and $F^{+}=2.06$ while for the configuration with the actuator is before the corner the parameters are $C_{\mu}$ $=1.8 \%$ and $F^{+}=1.66$. However, these two results give a similar overview of the flow with small differences close the actuator.

\section{References}

[1] J. Donovan, L. Kral, A. Cary, Active flow control appiled to an airfoil, in: 36th AIAA Aerospace Sciences Meeting, AIAA Paper 98-0210, Reno, NV, 1998.

[2] J. Ekaterinaris, Active flow control of wing separated flow, in: 4th ASME_JSME Joint Fluids Engineering Conference, no. FEDSM200345237, Honolulu, Hawaii, USA, 2003.

[3] R. Duvigneau, M. Visonneau, Optimization of a synthetic jet actuator for aerodynamic stall control, Computers \& Fluids 35 (2006) 624-638.

[4] A. Zymaris, D. Papadimitriou, K. Giannakoglou, C. Othmer, Optimal location for suction or blowing jets using the continuous adjoint approach, in: European Congress on Computational Methods in Applied SCiences and Engineering, ECCOMAS 2010, Lisbon, Portugal, 2010.

[5] E. Garnier, P. Pamart, J. Dandois, P. Sagaut, Evaluation of the unsteady RANS capabilities for separated flows control, Comupter \& Fluids 61 (2012) 39-45.

[6] J. Labroqure, R. Duvigneau, E. Guilmineau, Impact of turbulence closures and numerical errors for the optimization of flow control devices, in: 21st AIAA Computational Fluid Dynamics Conference, AIAA Paper 2013-2846, San Diego, California, USA, 2013.

[7] H. Jasak, H. Weller, A. Gosman, High resolution nvd differencing scheme for arbitrarily unstructured meshes, International Journal for Numerical Methods in Fluids 31 (1999) 431-449.

[8] B. Leonard, Simple high-accuracy resolution program for convective modelling of discontinuities, International Journal of Numerical Methods in Fluids 8 (1988) 1291-1318. 
[9] P. Queutey, M. Visonneau, An interface capturing method for freesurface hydrodynamic flows, Computers and Fluids 36 (2007) 14811510 .

[10] C. Rhie, W. Chow, A numerical study of the turbulent flow past an isolated aerofoil with trailing edge separation, AIAA Journal 17 (1983) $1525-1532$.

[11] R. Issa, Solution of the implicitly discretized fluid flow equations by operator-splitting, Journal of Computational Physics 62 (1985) 40-65.

[12] G. D. Deng, M. Visonneau, Comparison of explicit algebraic stress models and second-order turbulence closures for steady flow around ships, in: 7th Symposium on Numerical Ship Hydrodynamics, Nantes, France, 1999, pp. 4.4-1-4.4-15.

[13] R. Duvigneau, M. Visonneau, G. B. Deng, On the role played by turbulence closures in hull ship optimization at model and full scale, Journal of Marine Science and Technology 8 (2003) 11-25.

[14] E. Guilmineau, G. B. Deng, J. Wackers, Numerical simulation with a DES approach for automotive flows, Journal of Fluids and Structures 27 (2011) 807-816.

[15] C. Williams, Prediction with Gaussian processes: From linear regression to linear prediction and beyond, in: M. Jordan (Ed.), Learning in Graphical Models, Kluwer Academic, 1998, pp. 599-621.

[16] M. Gibbs, D. MacKay, Efficient implementation of Gaussian processes, Tech. rep. (1997).

[17] R. Duvigneau, P. Chandrashekar, Kriging-based optimization applied to flow control, International Journal for Numerical Methods in Fluids 69 (2012) 1701-1714.

[18] A. Thacker, R. Joussot, Présentation des premiers résultats expérimentaux sur le montage du GDR, Réunion du GDR Contrôle des décollements (juin 2012). 


\section{List of Figures}

1 Efficient Global Optimization loop . . . . . . . . . . . . . 12

2 Computational domain . . . . . . . . . . . . . . 13

3 Position of the synthetic jet . . . . . . . . . . . . 14

4 Computational domain . . . . . . . . . . . . . 15

5 Comparison of the velocity profile at $\mathrm{X} / h=-2.4$ for the non controlled configuration . . . . . . . . . . . . . . . . 16

6 Comparison of the streamlines for the non controlled configuration ........................ 17

$7 \quad$ Illustration of the initial sampling generating using LHS . . . 18

8 Optimization history . . . . . . . . . . . . . . . . . 19

9 Meta-model for the configuration A . . . . . . . . . . . 20

10 Meta-model for the configuration B . . . . . . . . . . . . 21

11 Streamlines of the averaged flow for the best controlled case . 22

12 Comparison of the pressure coefficient for the best controlled case and the non controlled case . . . . . . . . . . . . . . . 23

13 Streamlines over a cycle for the best controlled flow with the configuration A . . . . . . . . . . . . . . . . . . 24

14 Streamlines over a cycle for the best controlled flow with the configuration B . . . . . . . . . . . . . . . 25

15 Streamlines over a cycle for the best controlled flow with the configuration A . . . . . . . . . . . . . . . . . . 26

16 Streamlines over a cycle for the best controlled flow with the configuration B . . . . . . . . . . . . . . . . . . . . 27 


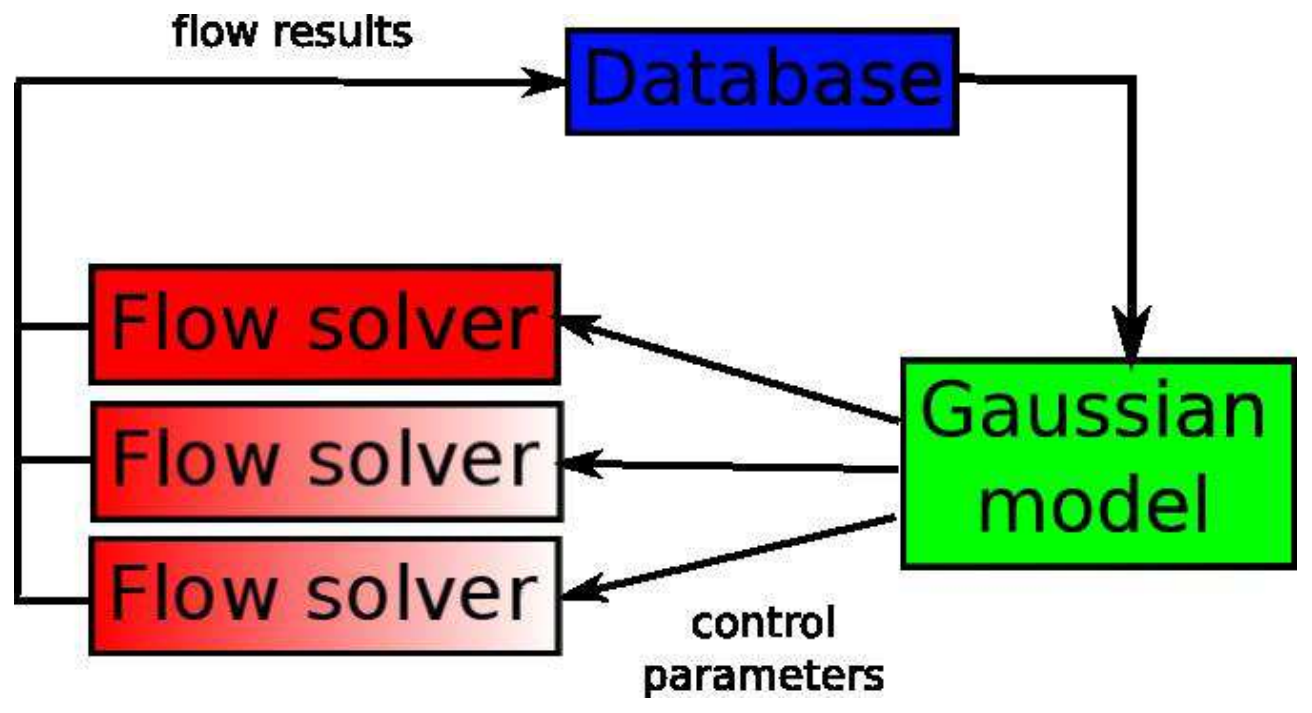

Figure 1: Efficient Global Optimization loop 


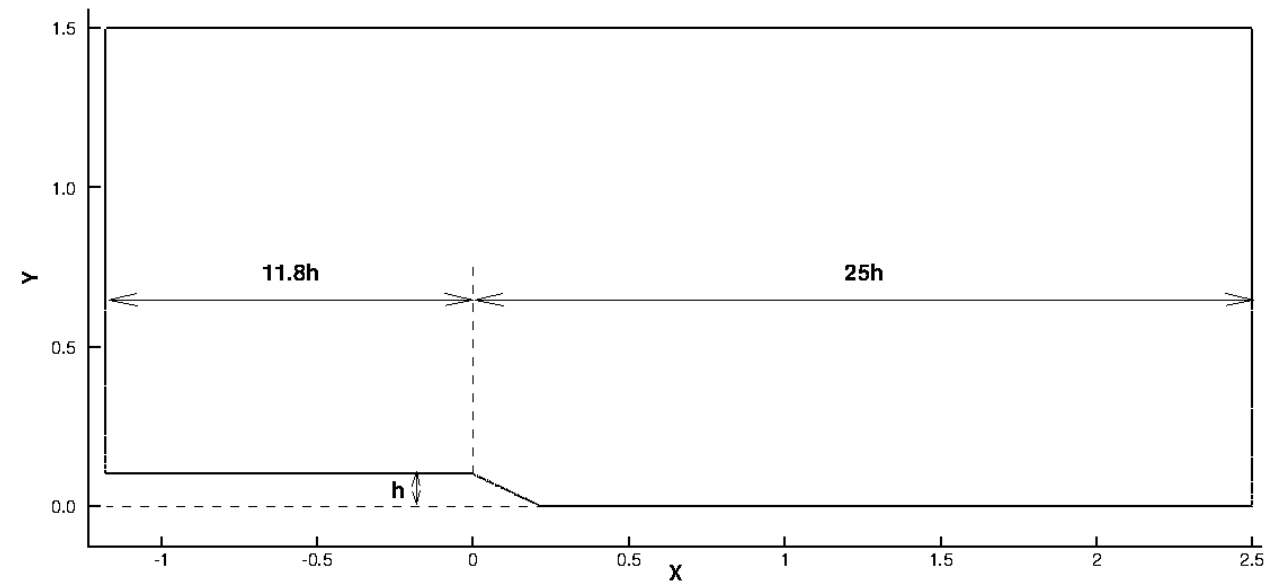

Figure 2: Computational domain 


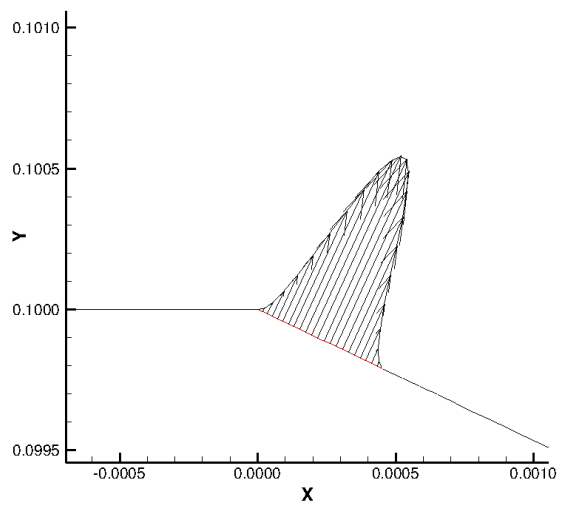

(a) Configuration $\mathrm{A}$

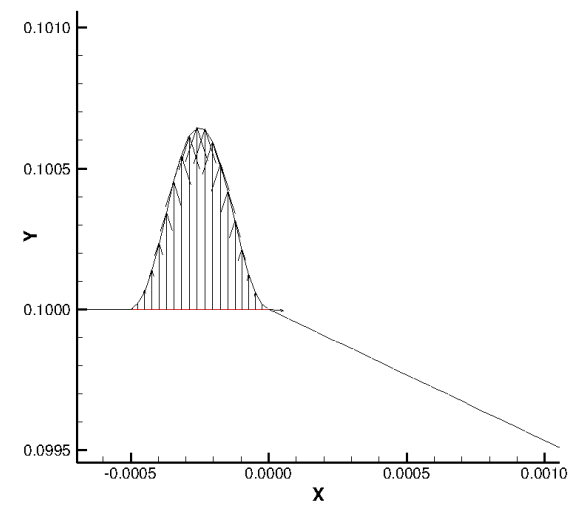

(b) Configuration B

Figure 3: Position of the synthetic jet 


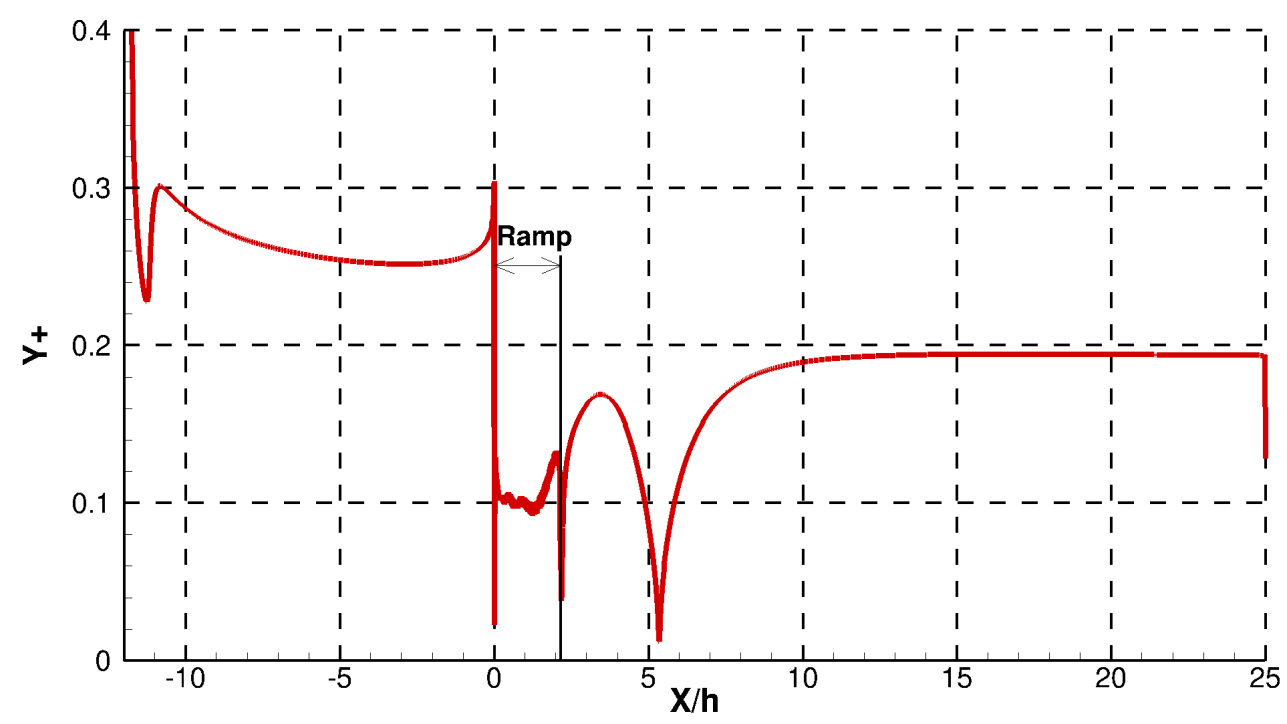

Figure 4: Computational domain 


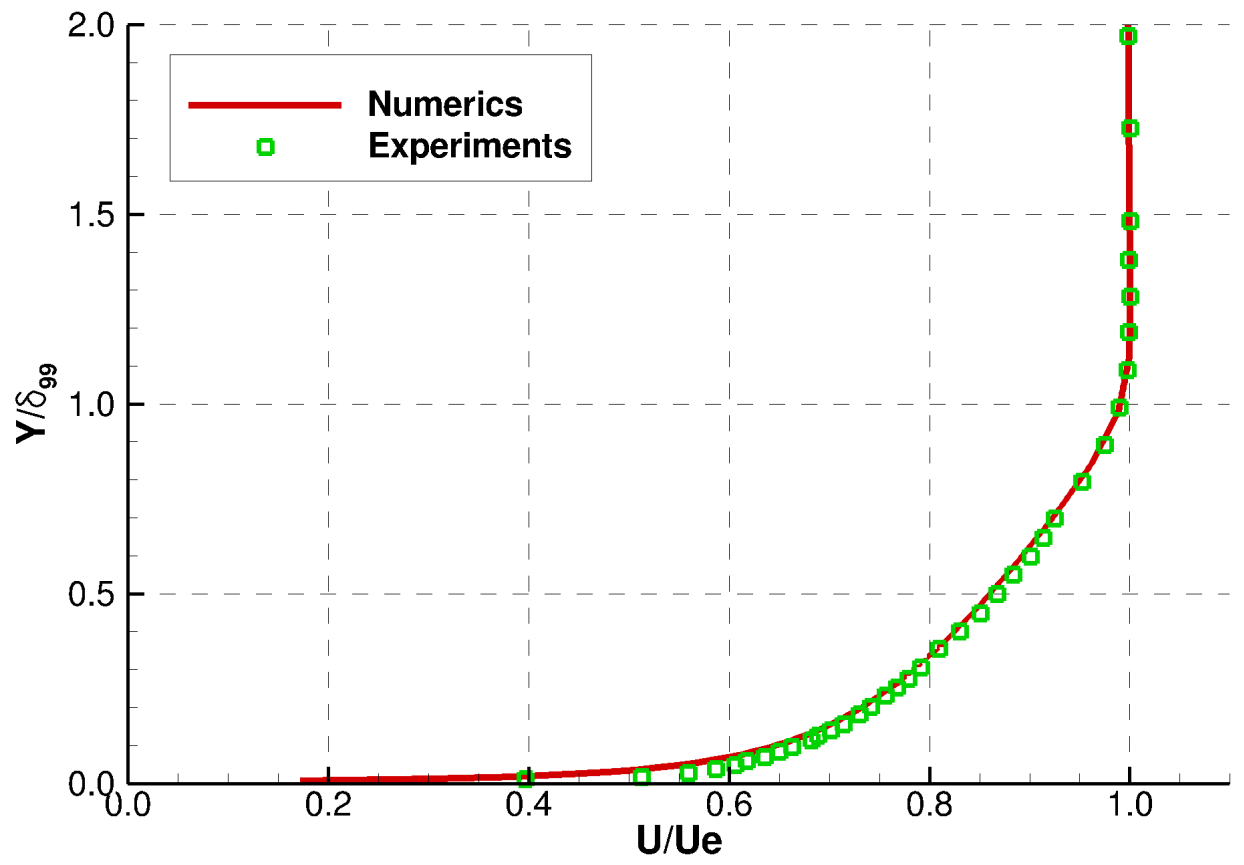

Figure 5: Comparison of the velocity profile at $\mathrm{X} / h=-2.4$ for the non controlled configuration 


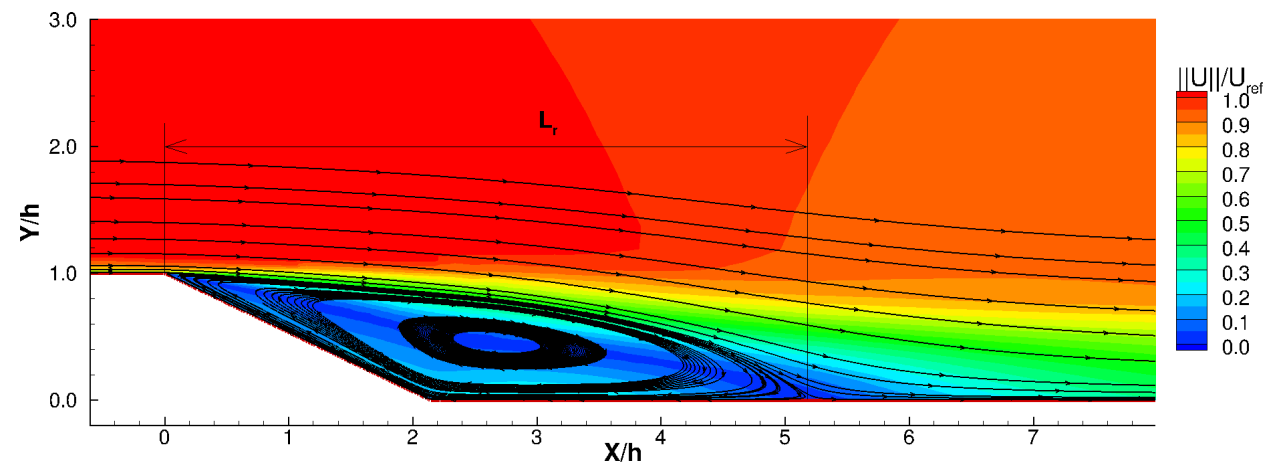

(a) Numerical result

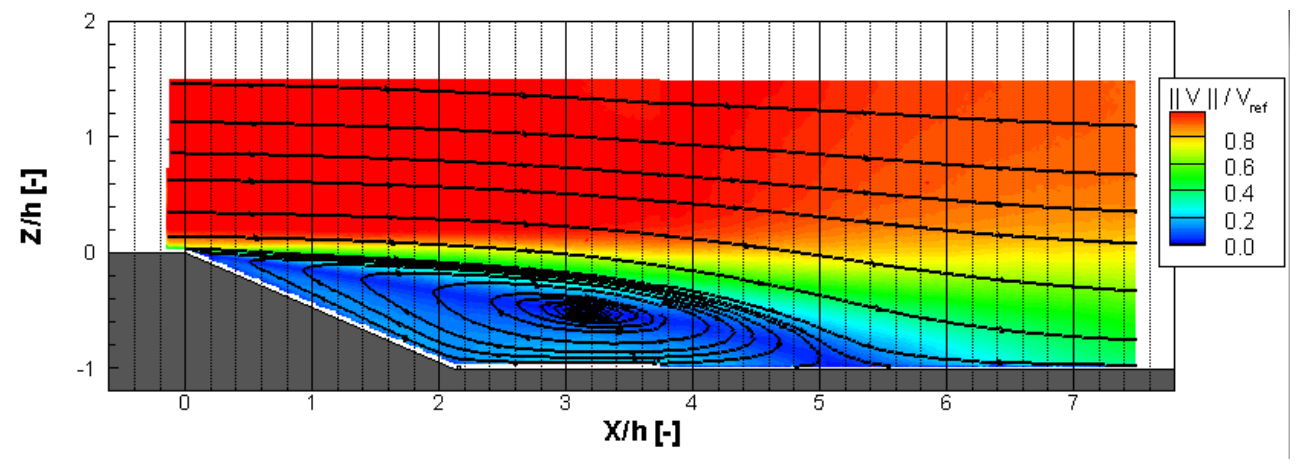

(b) Experimental result

Figure 6: Comparison of the streamlines for the non controlled configuration 


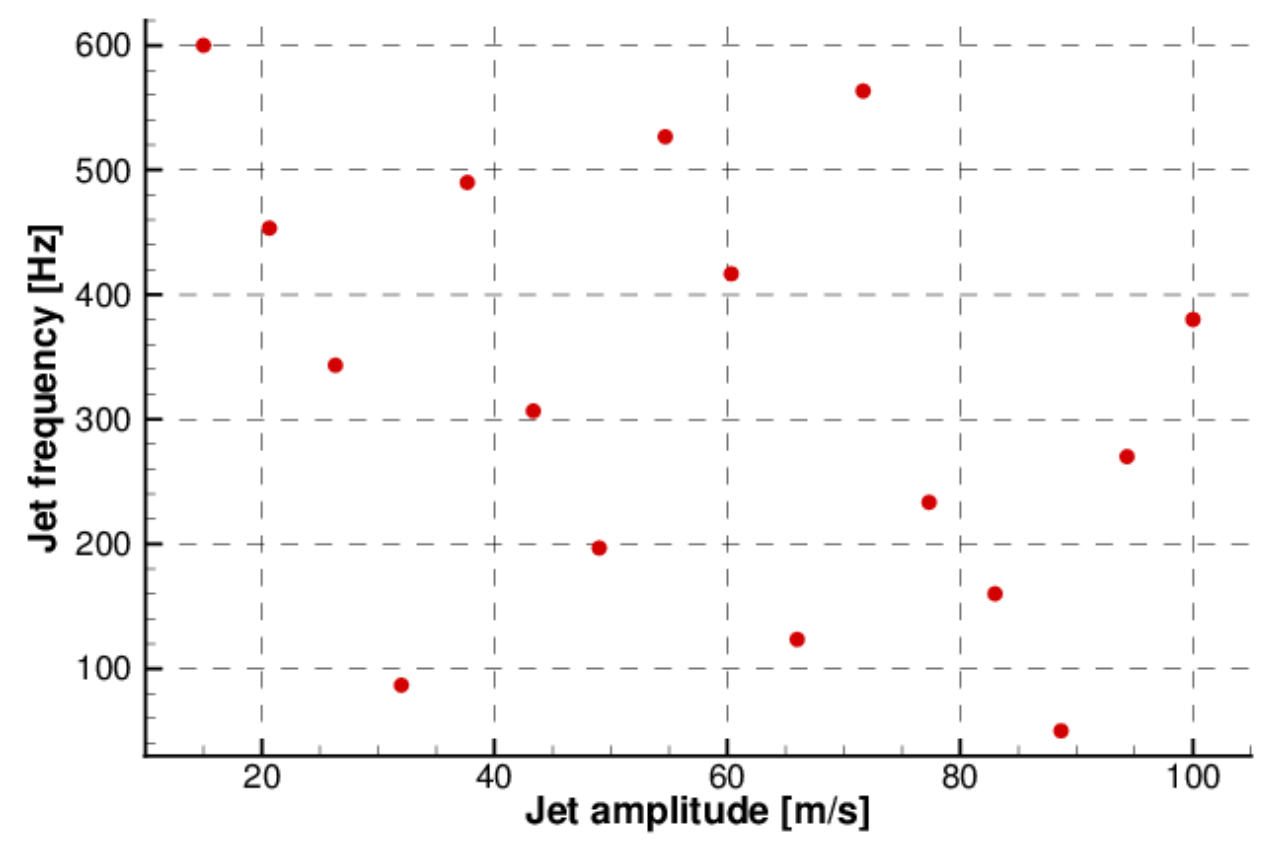

Figure 7: Illustration of the initial sampling generating using LHS 


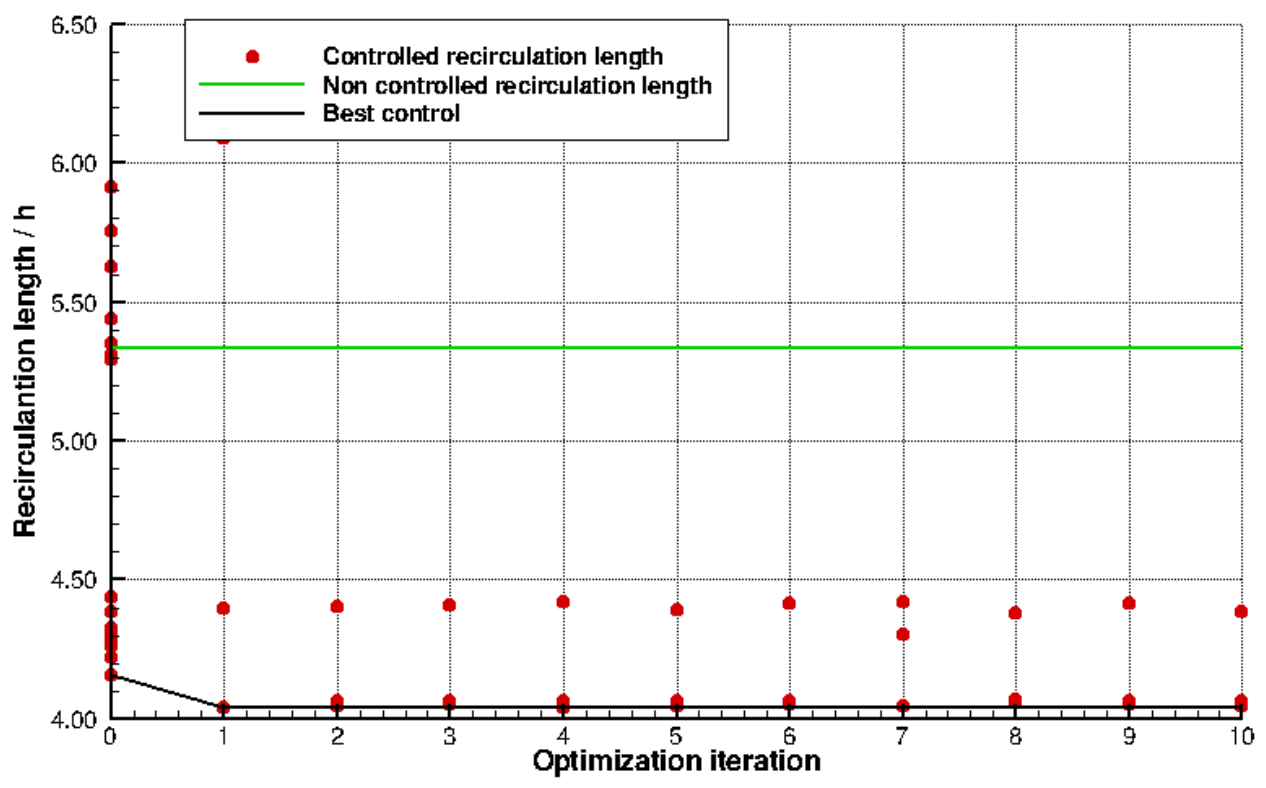

(a) Configuration $\mathrm{A}$

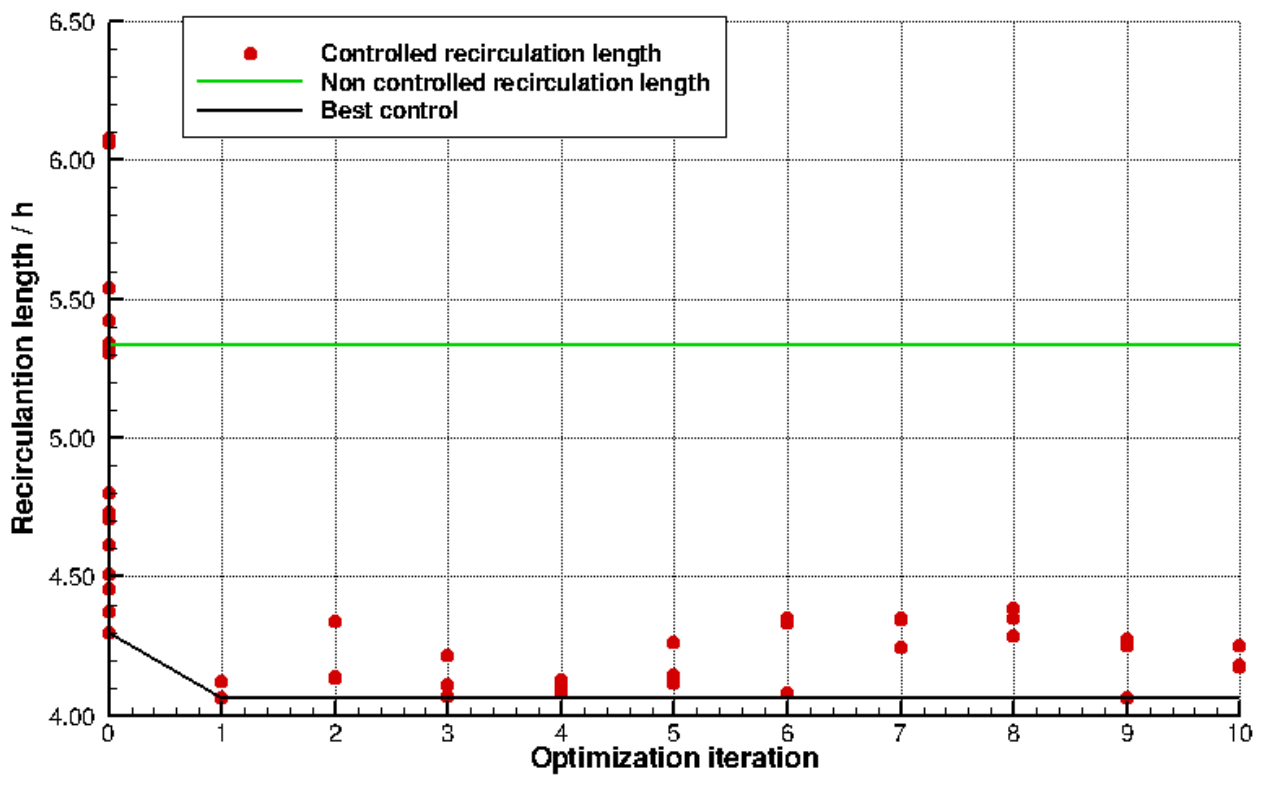

(b) Configuration B

Figure 8: Optimization history 


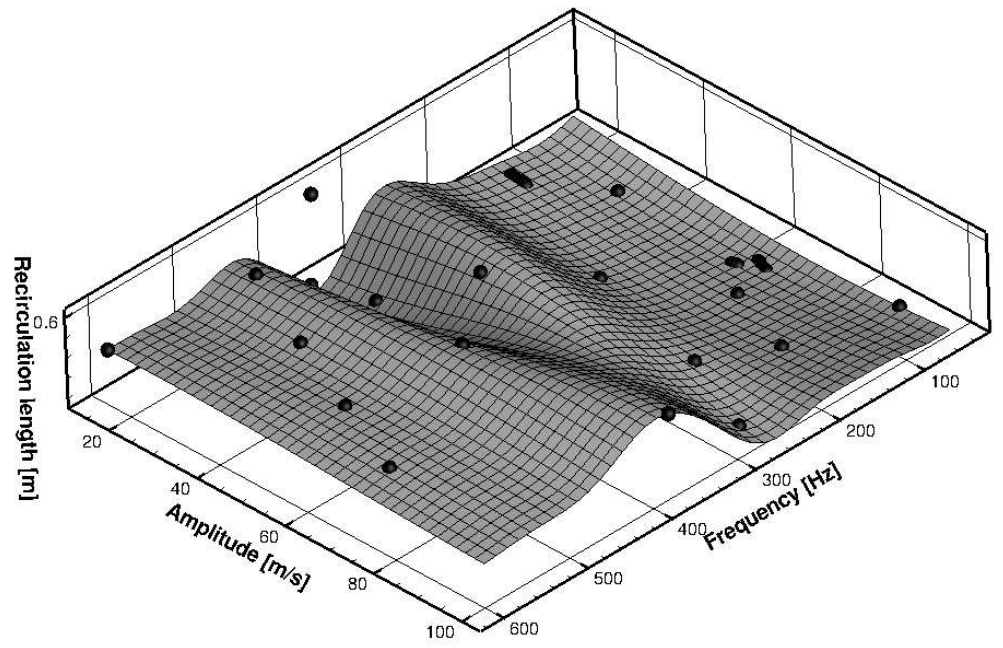

(a) $3 \mathrm{D}$ view

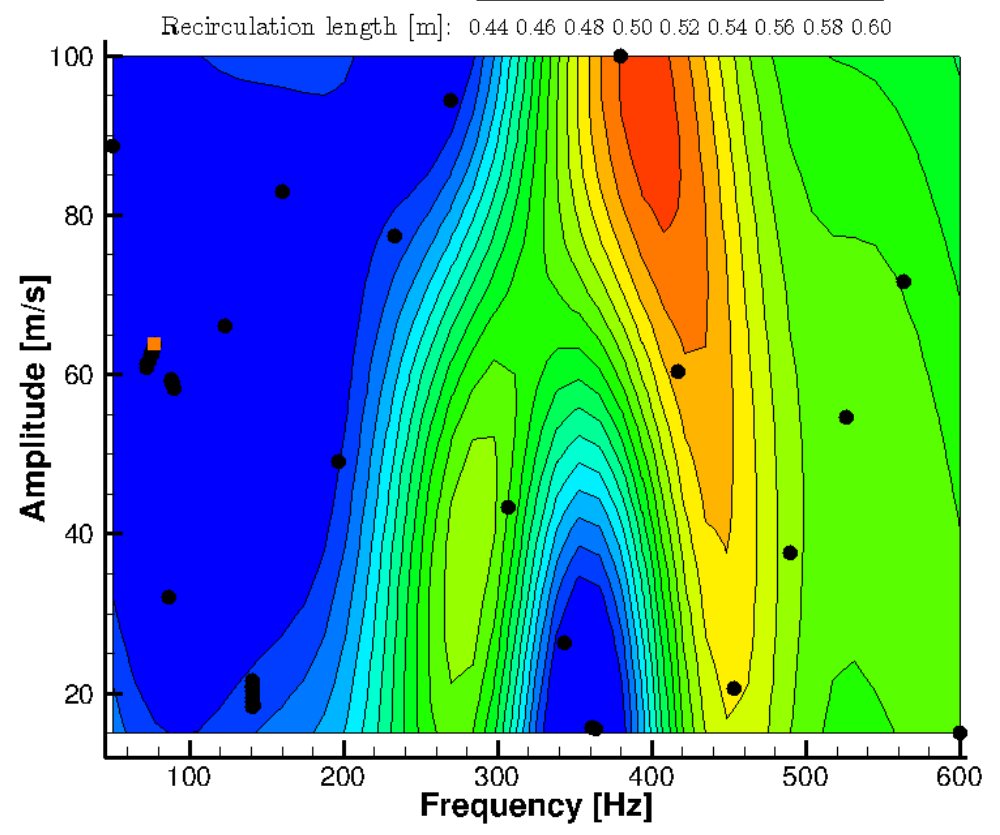

(b) $2 \mathrm{D}$ view

Figure 9: Meta-model for the configuration A 


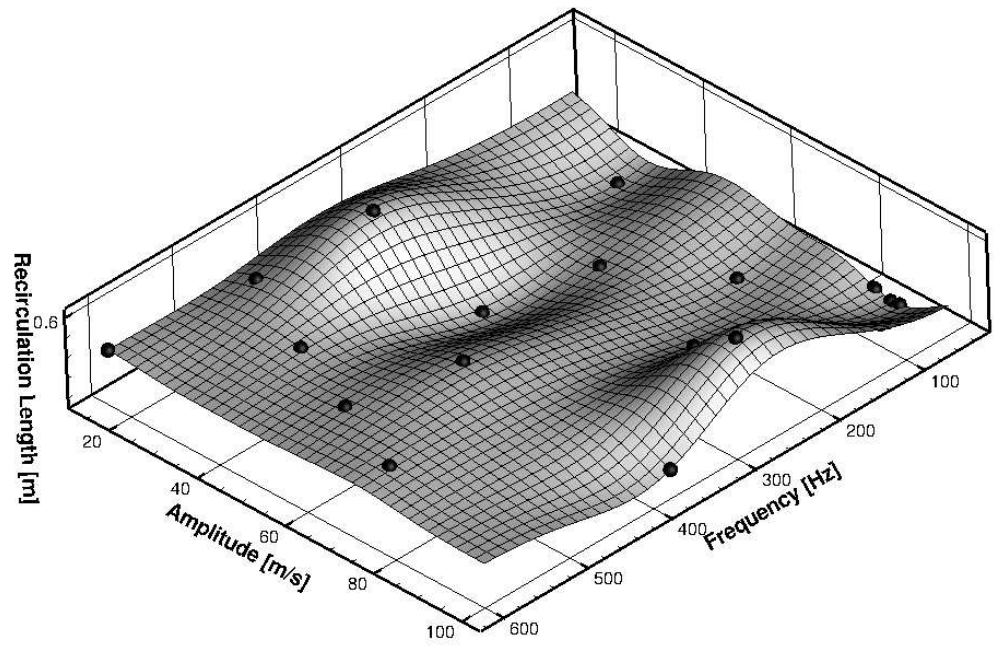

(a) 3D view

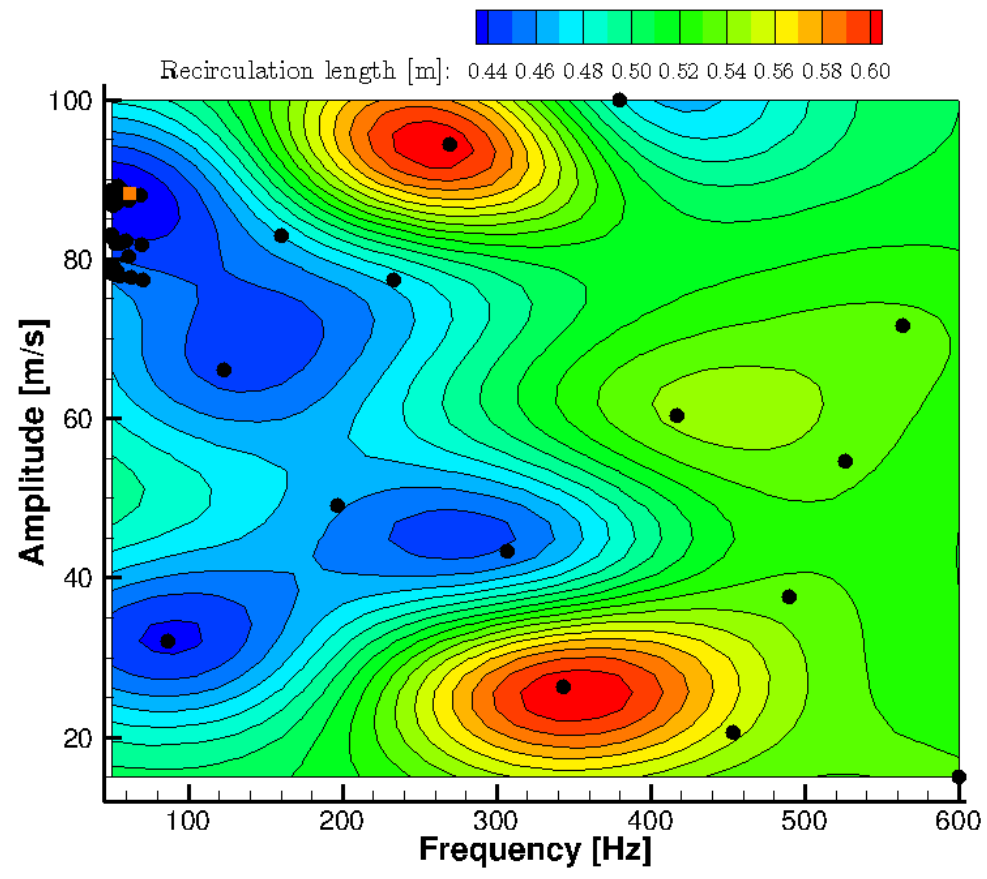

(b) $2 \mathrm{D}$ view

Figure 10: Meta-model for the configuration B 


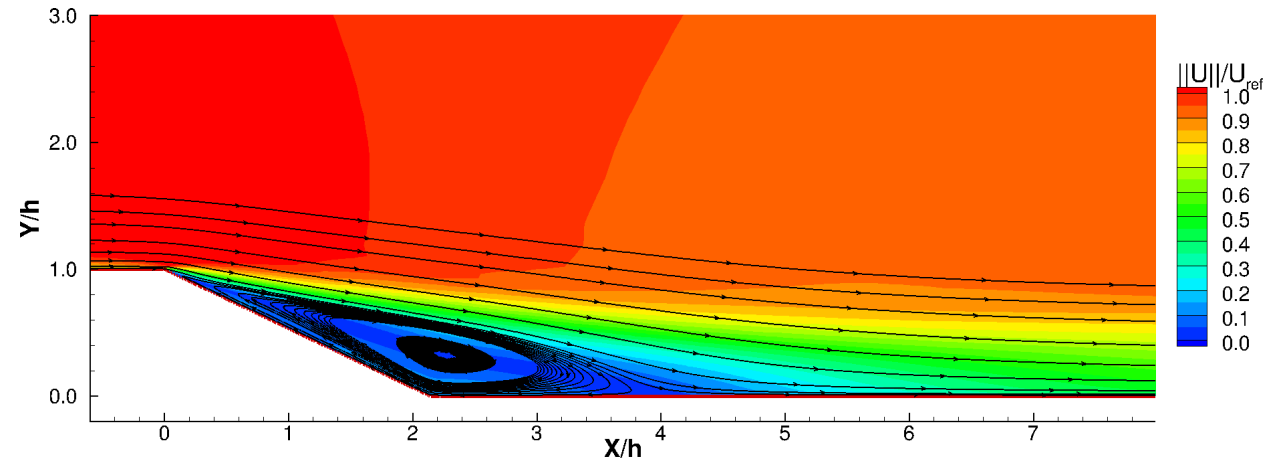

(a) Configuration $\mathrm{A}$

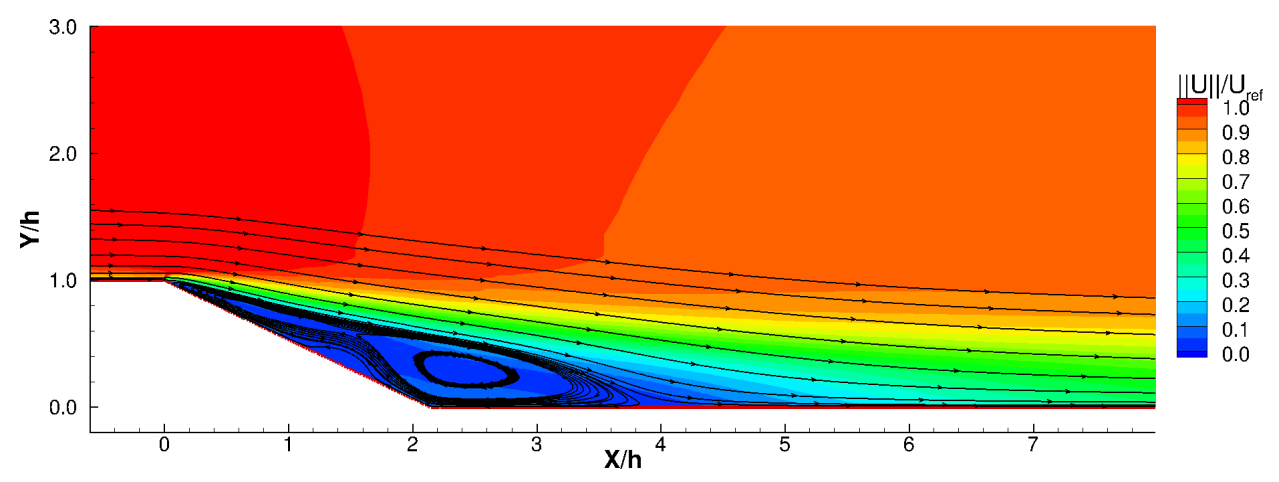

(b) Configuration B

Figure 11: Streamlines of the averaged flow for the best controlled case 


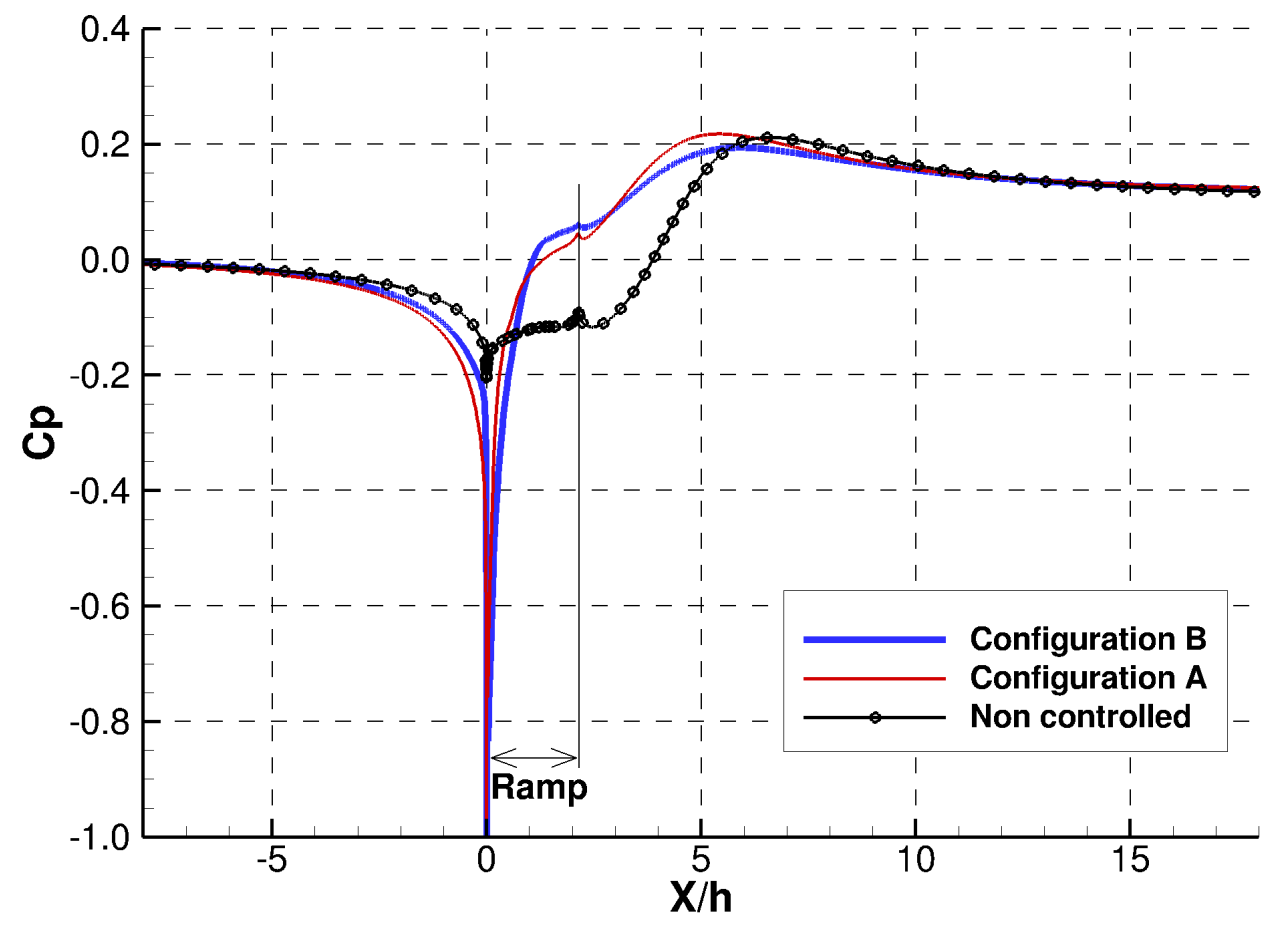

Figure 12: Comparison of the pressure coefficient for the best controlled case and the non controlled case 


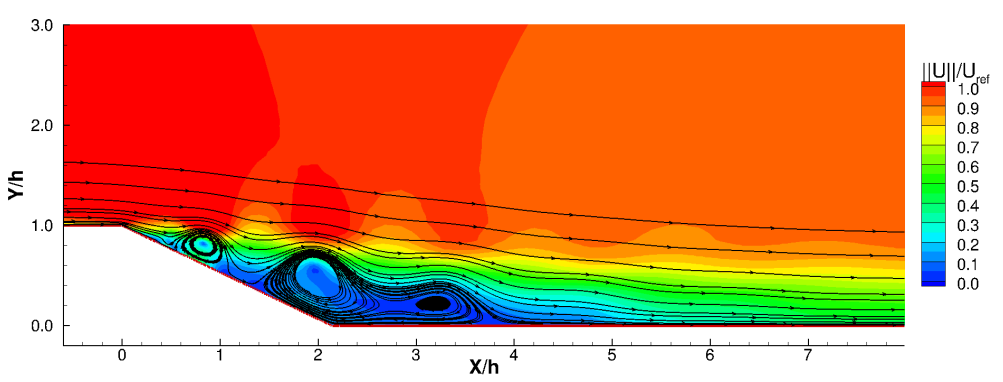

(a) t0

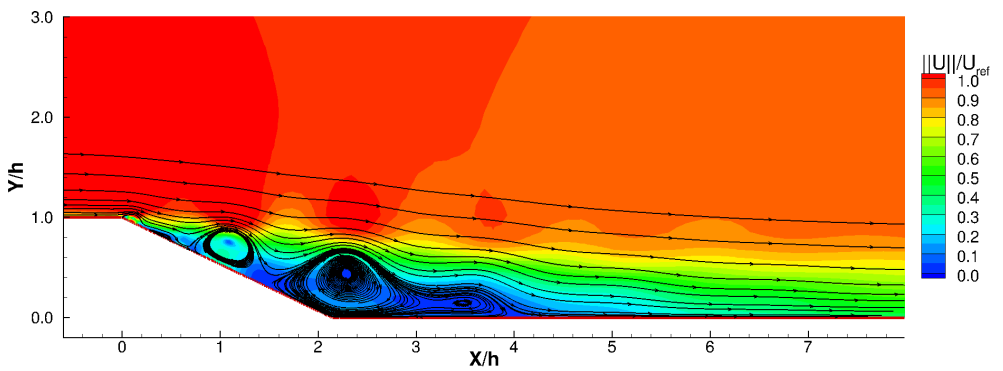

(b) $\mathrm{t} 0+\frac{1}{4} T_{j}$

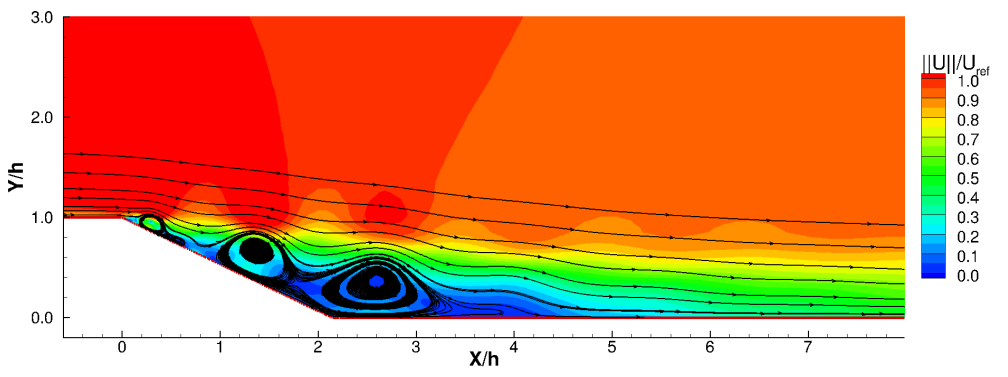

(c) $\mathrm{t} 0+\frac{2}{4} T_{j}$

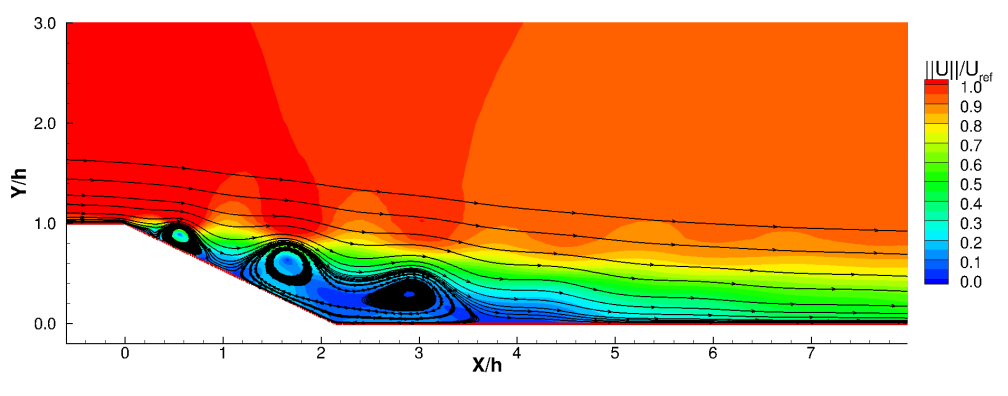

(d) $\mathrm{t} 0+\frac{3}{4} T_{j}$

Figure 13: Streamlines over a cycle for the best controlled flow with the configuration A 


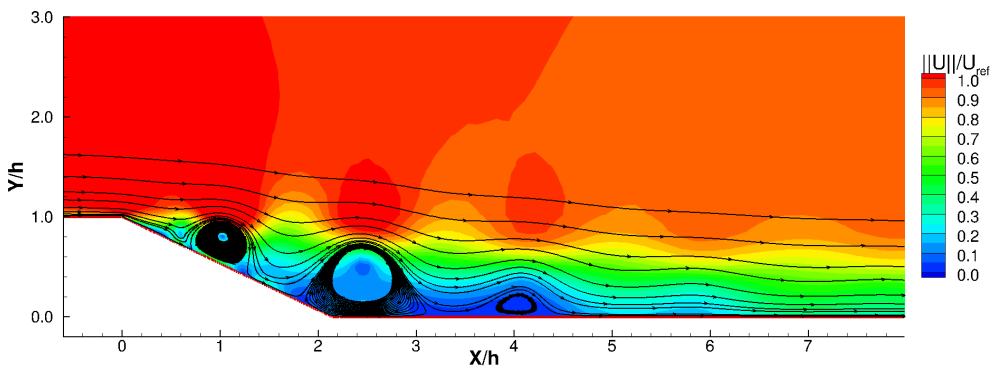

(a) t0

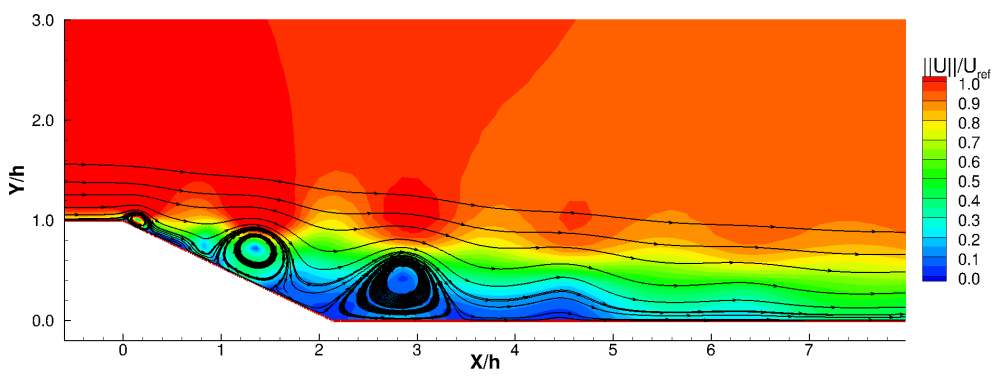

(b) t0 $+\frac{1}{4} T_{j}$

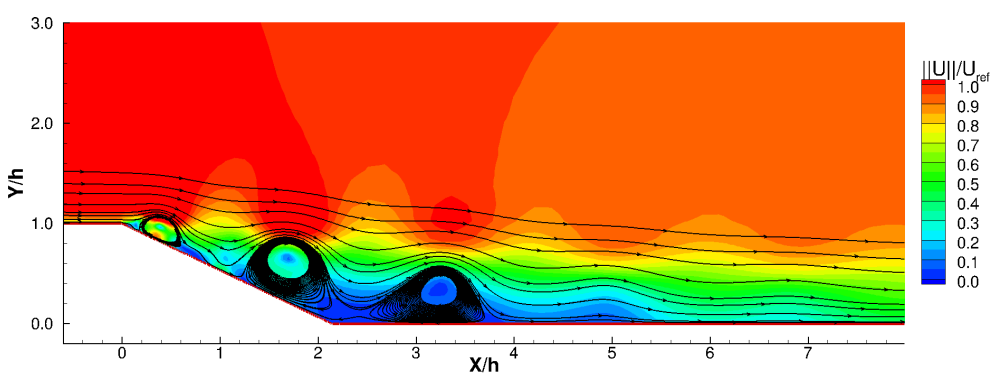

(c) t0 $+\frac{2}{4} T_{j}$

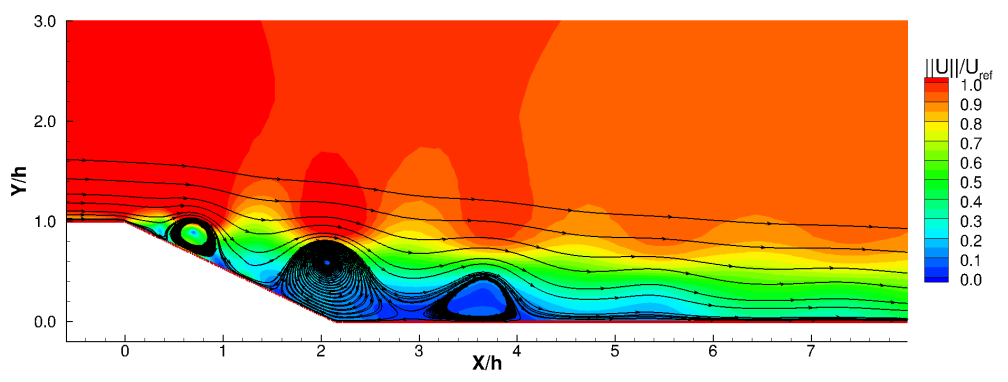

(d) $\mathrm{t} 0+\frac{3}{4} T_{j}$

Figure 14: Streamlines over a cycle for the best controlled flow with the configuration B 


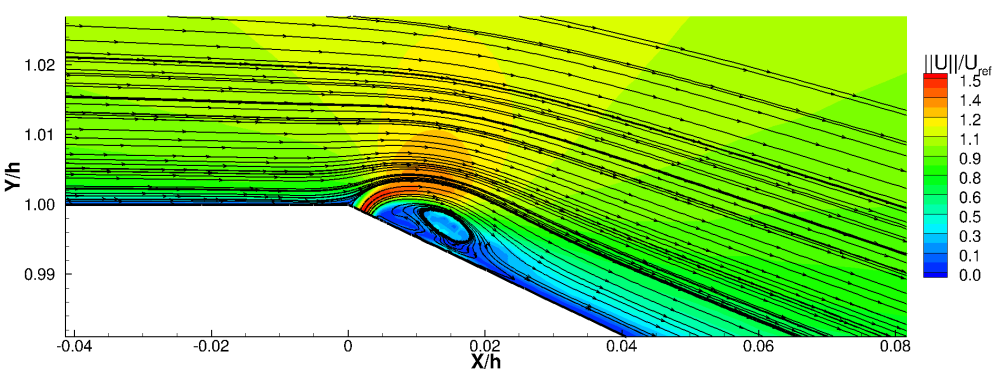

(a) t0

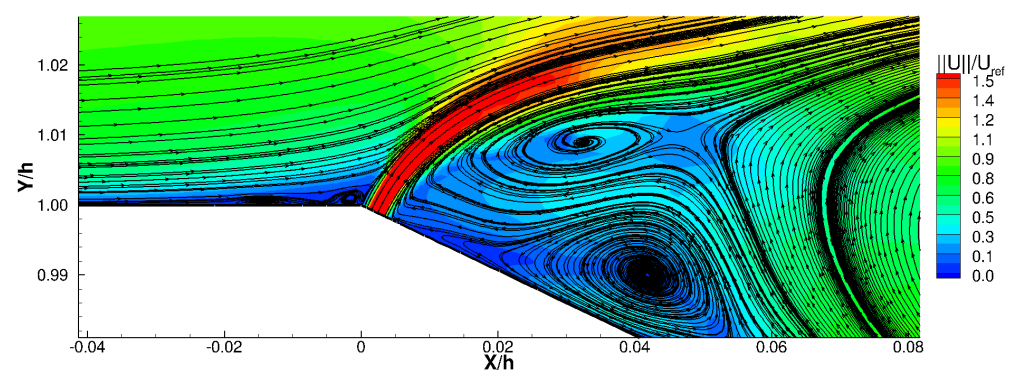

(b) t0 $+\frac{1}{4} T_{j}$

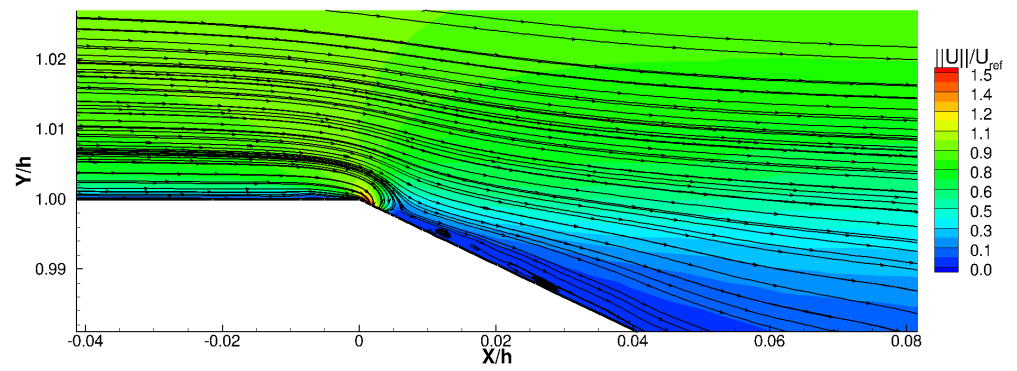

(c) t0 $+\frac{2}{4} T_{j}$

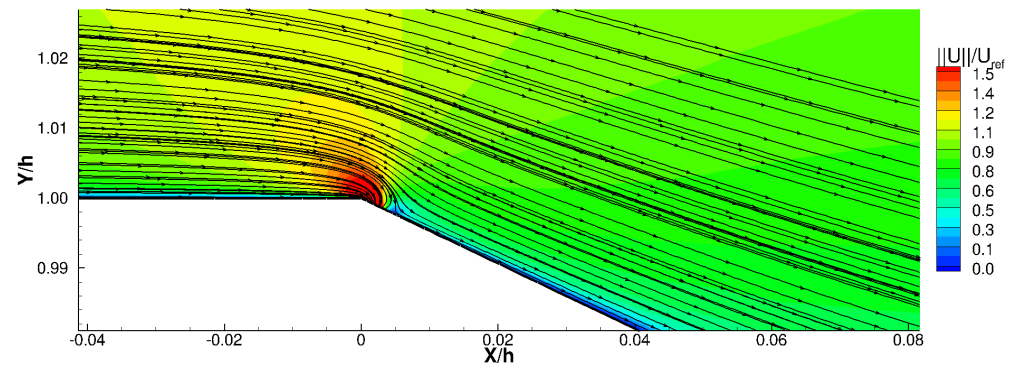

(d) $\mathrm{t} 0+\frac{3}{4} T_{j}$

Figure 15: Streamlines over a cycle for the best controlled flow with the configuration A 


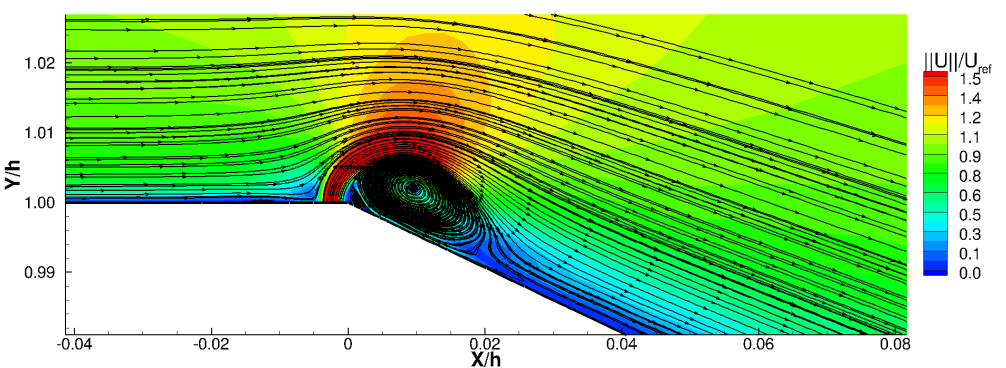

(a) t0

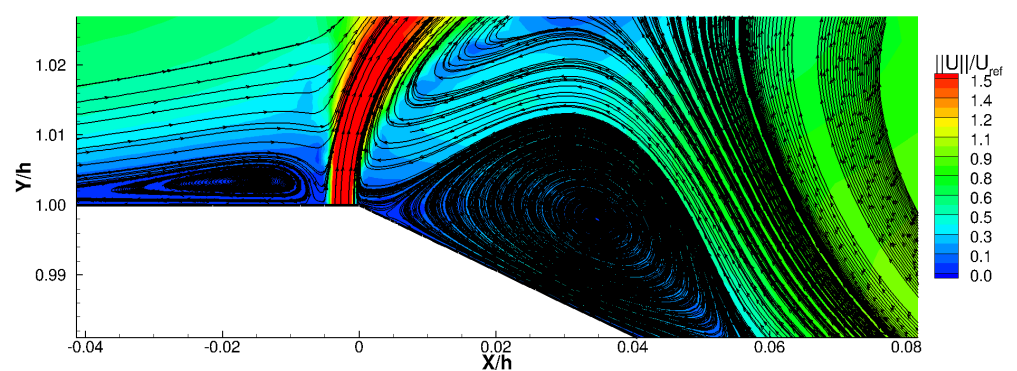

(b) t0 $+\frac{1}{4} T_{j}$

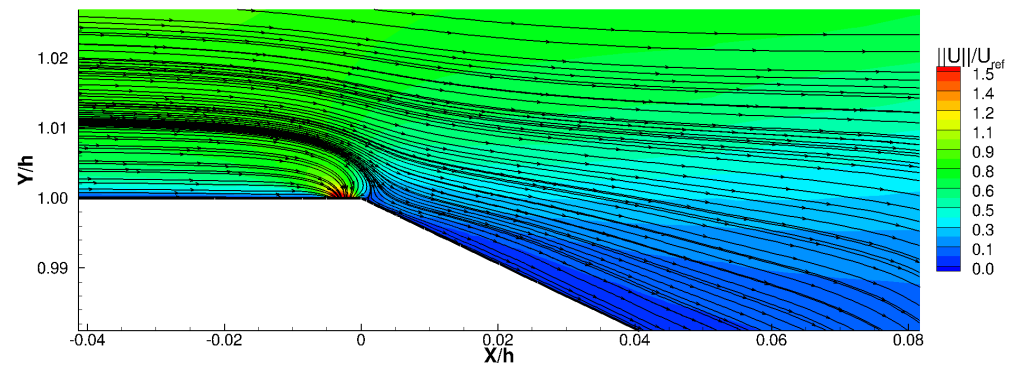

(c) t0 $+\frac{2}{4} T_{j}$

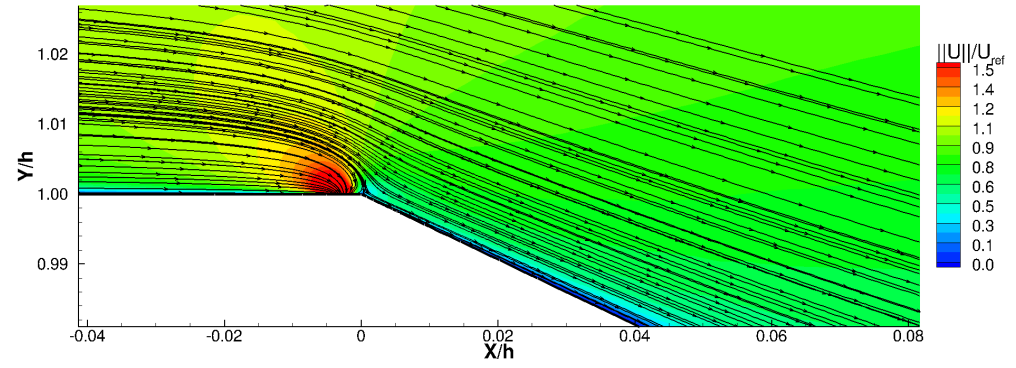

(d) $\mathrm{t} 0+\frac{3}{4} T_{j}$

Figure 16: Streamlines over a cycle for the best controlled flow with the configuration B 